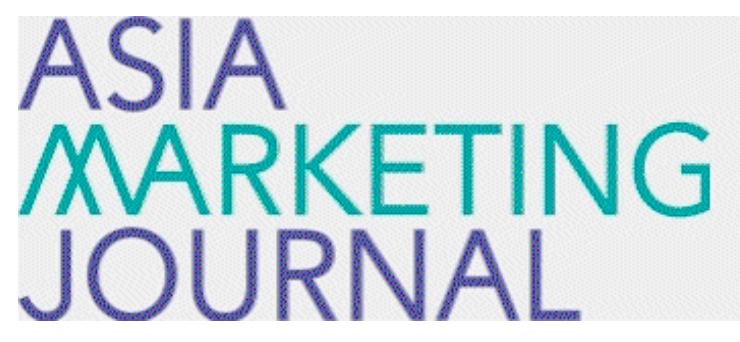

ASIA MARKETING JOURNAL

Volume 18 | Issue 2

Article 1

7-31-2016

\title{
Give a Man a Fish or Teach Him to Fish
}

Seo Young Kim

Youjae Yi

Follow this and additional works at: https://amj.kma.re.kr/journal

Part of the Marketing Commons

\section{Recommended Citation}

Kim, Seo Young and Yi, Youjae (2016) "Give a Man a Fish or Teach Him to Fish," Asia Marketing Journal: Vol. 18 : Iss. 2 , Article 1.

Available at: https://doi.org/10.15830/amj.2016.18.2.1

This Article is brought to you for free and open access by Asia Marketing Journal. It has been accepted for inclusion in Asia Marketing Journal by an authorized editor of Asia Marketing Journal. 


\title{
Give a Man a Fish or Teach Him to Fish: The Effects of Types of Help on Customer Satisfaction
}

\author{
Seo Young Kim* \\ Youjae $\mathrm{Yi}^{* *}$
}

\begin{abstract}
People receive support from others to solve problems that are difficult to solve on their own. During service encounters, customers also receive help from other customers. Inter-customer helping is a type of Customer Citizenship Behavior (CCB), which has become more prevalent with increased use of selfservice technologies (SSTs). However, not all helps are created equal. The current research investigates the effects of the two types of help, autonomy- and dependency-oriented help during service encounters. Autonomy-oriented help refers to a partial hint to the problem, whereas dependency-oriented help refers to the full solution to the problem. Through experimental studies, we provide evidence that depending on the types of help received during service encounters, customers show different levels of satisfaction toward the firm. The results from Studies 1A and 1B show that autonomy- (vs. dependency-) oriented help leads to higher customer satisfaction. In addition, the current research demonstrates the mechanism for such effect. The results from Study 2 show that the relationship between the types of help and customer satisfaction is mediated by instrumentality and anxiety, which represent cognitive and affective paths respectively.
\end{abstract}

Key words: inter-personal helping, inter-customer helping, customer citizenship behavior (CCB), types of help, customer satisfaction

\section{Introduction}

"Give a man a fish, and you feed him for a day. Teach a man to fish, and you feed him for a lifetime." - Chinese Proverb
Receiving help from others is critical in human survival. People receive support and advice from others to solve problems that are difficult to solve on their own. During service encounters, customers also receive help from

* Doctoral Candidate, College of Business Administration, Seoul National University (seoyoung.kim09@gmail.com)

** Professor of Marketing, College of Business Administration, Seoul National University (youjae@snu.ac.kr), Corresponding Author 
other customers to solve difficulties in service deliveries. Inter-customer helping during service encounters is a type of Customer Citizenship Behavior (CCB), which has been highlighted previously in the services marketing literature (e.g., Yi and Gong 2008a; Yi and Gong 2008b), and has become more prevalent with increased use of self-service technologies (SSTs). Customers are replacing the roles of employees, and such customer engagement leads to customer value creation (Yi 2014). However, do all helps lead to customer value creation? As illustrated in the quote above, receiving different types of help leads to differential effects in one's life. Likewise, receiving different types of help from other customers during service encounters would also lead to different consequences. In fact, depending on the types of help, inter-customer helping could sometimes be detrimental to the recipients and thus, not creating value. The current research investigates two specific types of help, autonomy- and dependency-oriented help, and their influences during service encounters to provide important insights to the services marketing literature. Autonomy-oriented help refers to the partial hint to the problem that teaches the recipient how to fish, and dependency- oriented help refers to the full solution to the problem that directly gives the recipient a fish.

Previous literature on the types of help paid attention to the conditions under which people decide to provide these types of help during inter-group helping contexts. The helper's ex- pectation of the recipient's ability is one important driver for the helper's decision making (Brickman et al. 1982). Most studies on the types of help focused on the helper rather than the recipient, and focused on the antecedents for the behavior rather than the consequences. The purpose of the current research is to focus on the recipient's side to examine the consequences of receiving help from other customers during service encounters. While both autonomyand dependency-oriented help enable recipients to solve problems, they differ in their dependence towards the helper as seen in the quote above. Autonomy-oriented help allows recipients to retain their independence compared to dependency-oriented help (Nadler 1997), and thus, enables the recipients to solve the problem while maintaining their self-esteem. This difference in dependence and self-esteem is known to cause different consequences. The current article makes an effort to implement the findings from the inter-group helping literature to the services marketing literature to provide important academic and practical insights. Specifically, in addition to investigating the effect of the types of help on customer satisfaction during service encounters, we investigate the mechanism behind such effect to deepen our understanding.

The current research contributes to the academia in twofold. First, the current research contributes to the helping literature through extending the findings on the types of help in 
service settings. In particular, previous research on the types of help focused on inter-group helping interactions (e.g., Nadler 2002), and investigation of the types of help in inter-personal helping interactions is relatively limited. We examine the effect of types of help during inter-customer relationships to fill this gap in the literature. The current research serves as an initial effort to investigate the types of help in inter-personal helping during service encounters, and more importantly, investigate whether the self-related mechanism still holds in this situation. Second, the current research adds valuable insights to the CCB literature through focusing on the recipients' reactions. Despite extensive investigations on $\mathrm{CCB}$ in the services marketing literature, there is rather limited knowledge on the recipients' reactions to CCB. This research focuses on inter-customer helping, a type of CCB during service encounters. Unlike employee assistance, which is an in-role behavior that is part of the service delivery, inter-customer helping is a voluntary extra-role behavior. Inter-customer helping is a meaningful phenomenon that has become important with increased customer participation.

Through three experimental studies, we investigate the differential effects of the two types of help during service encounters. In Studies 1A and $1 \mathrm{~B}$, we investigate the effect of the types of help on customer satisfaction. Specifically, we show that autonomy-oriented help leads to higher customer satisfaction. In Study 2, we further investigate the relationship between the types of help and customer satisfaction through examining (1) why autonomy-oriented help leads to higher satisfaction, and (2) for whom the effect is stronger. Specifically, we suggest a dual mechanism for the relationship between the types of help and customer satisfaction. We examine instrumentality and anxiety as the two mediators that represent cognitive and affective mechanisms respectively. In addition, the results from Study 2 also show that the relationship between the types of help and customer satisfaction is stronger for those lower in their need for dominance, suggesting that not all people would be affected equally by the types of help.

The rest of the paper is organized as follows: In the subsequent section, relevant literature is reviewed to derive hypotheses. Hypotheses are tested through three experimental studies. Finally, the theoretical and managerial implications are discussed, as well as suggestions for future research.

\section{Literature Review}

\subsection{Receiving Help from Other Customers}

Customers are "partial employees" and often engage in helping other customers in service settings (Miao and Mattila 2013). These "partial employees" recall their own experiences, and thus show a sense of social responsibility to help others 
(Rosenbaum and Massiah 2007). Helping each other became even more common due to the replacement of the traditional service encounters with SSTs because employees are not always present during such service deliveries. Inter-customer helping during service encounters is a type of CCB, which refers to a discretionary, voluntary extra-role behavior during service encounters that also helps the organizations (Groth 2005). Groth (2005) has identified three dimensions of CCB: (1) providing feedback to the organization, (2) recommendation of the business to friends or family members, and (3) helping other customers, which is equivalent to inter-customer helping discussed in the current research. Understanding this particular type of CCB has become critical because more customers are seeking and providing assistance in delivering the services. Accordingly, a few researchers in the services marketing field have recently paid attention to this phenomenon. Among them, Sigala (2009) has investigated inter-customer support in the web 2.0 contexts, and Rosenbaum and Massiah (2007) have demonstrated the effect of inter-customer support on individual's decision to engage in other CCBs. However, still many research questions regarding this topic remain unanswered, which are worthy of investigation.

In the current research, we focus on the consequences of receiving help from other customers, which is relatively neglected in the literature. When providing help, customers expect that their help would always lead to positive outcomes to the recipients. However, receiving help would not always create the same consequences, and in fact, can be threatening at times (e.g., Nadler et al. 1979). There is evidence from organization behavior research that receiving instrumental support can result in negative self-related reactions such as competence-based self-esteem (Deelstra et al. 2003), and thus encouraging inter-customer helping would not always benefit all parties. Then, one question arises: when are customers more satisfied with receiving help from others? In the present study, we suggest that customers' reactions to receiving help would differ depending on the types of help.

\subsection{Types of Help: Autonomy- vs. Dependency-oriented Help}

Because receiving help can be threatening at times due to the inequality between the helper and the recipient in their resources (Nadler et al. 1979), it is worthwhile to investigate which type of help leads to greater satisfaction among the recipients. We especially focus on the two types of help, autonomy-oriented help and dependency-oriented help. Autonomy-oriented help refers to the partial and temporary solution to the problem (Nadler 1997), such as instructions or hints to the problem. On the other hand, dependency-oriented help refers to the full solution to the problem at hand. One could easily understand this distinction by associating the 
autonomy-oriented help with "teaching him to fish,' and the dependency-oriented help with 'giving him the fish.' The inter-group helping research often investigated this distinction because of its relation to status and power relations (Nadler and Halabi 2006). Nonetheless, such status and power relations are also present during inter-customer helping contexts due to asymmetry in information and knowledge. Therefore, investigating the effects of the two types of help during service encounters would add meaningful insights to the services marketing literature.

Previous research on the types of help focused on help seeking. For example, helpers determine which kind of help to offer depending on the recipients' ability to help themselves (Brickman et al. 1982). Dependency-oriented help is more likely to be given to those who are relatively weak in their abilities. On the other hand, autonomy-oriented help is more likely to be given to those who are relatively competent. People often seek autonomy-oriented help to maintain positive impressions (van Leeuwan et al. 2010) and avoid dependency-oriented help due to its potential threat to self-esteem (Alvarez and van Leeuwan 2011). People often view being dependent on help less favorably due to its negative inference to individual achievements and competence (Karabenick 1998). Most studies established consensus in that autonomy-oriented help is more effective in that it allows recipients to retain their independence while helping recipients to solve the problem (Nadler 1997). However, there exist situations where retaining independence or self-esteem is not as critical, and we suggest that service encounters are one of those. Autonomy is considered to be more important during relational conflicts compared to task conflicts (van Leewan, Tauber, and Sassenberg 2011), and during task conflicts such as service deliveries, customers are less likely to focus on retaining their autonomy and/or maintaining their self-esteem. Due to the low severity of the issue, receiving help from other customers during service encounters would be less threatening compared to other situations such as receiving academic support from other students. Service encounters are not as severe because it is less likely that others will evaluate your competence based on your ability to deliver successful services. Thus, we suggest that self-related mechanism might not work in this situation, and thus, propose different mechanisms for the relationship between the types of help and customer satisfaction.

\subsection{Cognitive and Affective Paths to Customer Satisfaction}

Customers during service encounters are expected to focus on two different mechanisms, which are instrumentality and anxiety that represent cognition and affect respectively. A number of satisfaction studies supported the cognitive explanation (e.g., Oliver and Swan 1989), 
and others have supported the affective explanation (e.g., Mooradian and Olver 1997). Nonetheless, Homburg and colleagues (2006) have found that both cognition and affect significantly predict satisfaction judgments. Because customers rely on both cognitive and affective signals from the service provider as an indicator of service quality (Johnson and Grayson 2005), a consideration of both aspects is critical in investigating customer satisfaction. In the current setting, instrumentality of the help represents the cognitive path to customer satisfaction, and anxiety for future usage represents the affective path to customer satisfaction. Thus, we suggest a dual path model in the relationship between the types of help and customer satisfaction.

First, we suggest a path that is focused on the cognitive evaluation of the situation, which we call the "Cognitive Path." When pursuing a certain goal, individuals usually assess how instrumental a means is in achieving the goal (Labroo and Kim 2009). Instrumentality refers to the perceived relationship between a certain behavior and outcomes, such as reward, and instrumentality is an important motivator of extra-role behaviors and other goal attainment behaviors (Hui, Lee, and Rousseau 2004). Various studies in goal attainment have reported that increased instrumentality leads to increased motivations toward goals. In the current research, we suggest that instrumentality is also an important factor that mediates the relationship between inter-customer helping and customer satisfaction. Customers who have received help from other customers will be satisfied depending on how they perceive such help would lead to specific positive outcomes, problem solving and/or successful service delivery. Previous research has found that individuals with active goals evaluate instrumental others more positively, maintain closer relationships with them, and approach them more readily (Fitzsimons and Shah 2008). In a similar vein, we propose that individuals receiving help from other customers during service encounters will be more satisfied when received help is higher in its instrumentality.

Next, the second path focuses on customers' emotional responses, which we call the "Affective Path." In this path, customers focus their attention on the affective reactions to the problem. Because most services are used in a daily routine, most customers would consider using it again in the future. We specifically argue that customers would feel anxious when receiving help from others because of the uncertainty associated with their future usage. Anxiety is an emotion focused on anticipation of future events, which is distinct from other emotions that are rather immediate, such as fright (Lazarus and Averill 2013). Studies on anxiety mostly have focused on anxiety disorders, which is an individual characteristic. A few studies have examined the state anxiety felt in certain contexts, such as learning a second language (MacIntrye 2002) or public speaking (Egloff et al. 2006). 
In the current research, we focus on the state anxiety felt when receiving help from another customer during service encounters. In this path, customers feel the anxiety for future usage, and this affective path would lead to decreased customer satisfaction because anxiety is a negative emotion that would lead to dissatisfaction (Zeelenberg and Pieters 2004). Taken together, we hypothesize that the relationship between the types of help and customer satisfaction would work in a dual pathway, containing both the cognitive and affective paths.

\section{$H_{1}$ : Receiving autonomy- (vs. dependency-) oriented help leads to higher customer satisfaction. \\ $\mathrm{H}_{2-1}$ : Receiving autonomy- (vs. dependency-) oriented help leads to higher customer satisfaction due to higher perceived instrumentality. \\ $\mathrm{H}_{2-2}$ : Receiving autonomy- (vs. dependency-) oriented help leads to higher customer satisfaction due to lower anxiety for future usage.}

However, not all people would be affected by the types of help in the same way. For some people the types of help would not matter, and for others, the effects of types of help would be stronger. Here, we suggest that the need for dominance would play a role in the relationship. Need for dominance refers to the desire to control the environment and the desire for au- tonomy (Gough 1975). The act of helping is often threatening to the recipient's need for autonomy and perceived control (Nadler 2002), and perceived control is a prerequisite for effective helping (Coates, Renzaglia, and Embree 1983). Reactance theory also suggests that the motivation to avoid loss of control would deter one from seeking help (Brehm 1966). Therefore, the need for dominance is likely to affect the experience of receiving help. Receiving help from others regardless of the types of help would cause negative reactions for individuals with higher need for dominance. Most studies on need for dominance have been conducted in organizational settings, especially regarding leadership (e.g., Bartol 1974). However, need for dominance may be an important individual characteristic in the inter-personal helping setting. Because individuals seeking help tend to perceive lower levels of perceived control over the problem (Simon, Adelman, and Nelson 1991), when customers need other customers' assistance to deliver the services, they have already lost full control of the situation.

Thus, we propose that for individuals high in their need for dominance, such circumstances would already have violated their needs for having full control over the situation, and thus, they would be less affected by the types of help received. On the other hand, for individuals lower in their need for dominance, the degree of perceived control would differ contingent on the types of help they receive from the helper. 
In other words, the effect would be stronger for those low (vs. high) in their need for dominance for the dual mechanism model. Therefore, we hypothesize the following:

$H_{3-1}$ : For those low (vs. high) in need for dominance, the relationship between the types of help and perceived instrumentality would be stronger.

$H_{3-2}$ : For those low (vs. high) in need for dominance, the relationship between the types of help and anxiety would be stronger.

\subsection{Research Context: Self-Service Technologies (SSTs)}

The current research investigates the effect of types of help on customer satisfaction especially in SST settings, and the reasons are as follows. First, SSTs, such as ATMs, self checkout services at groceries, and pay-at-the-pumps, are replacing the traditional face-to-face service encounters. Customers prefer using the SSTs instead of the traditional service encounters because they are convenient (Meuter et al. 2000), and save time and cost (Meuter and Bitner 1998). Firms also benefit from implementing SSTs due to reduced labor costs (Mills and Morris 1986). Therefore, understanding consumer behavior during their SST usage has become more important in the current market place.

Second, increased interactions between cus- tomers are another unique characteristic of SSTs. For SST users, their need for human interaction is minimal, and they focus on the speed and the accuracy of an SST to be satisfied with the service (Collier and Kimes 2013). However, during SST usage, firms are in a difficult position in promptly assisting customers when they need help, and thus the role of other customers becomes more important. Much research effort in customer participation during SST usage focused on the user's participation (e.g., Kelly, Lawlor, and Mulvey 2013). However, in the current research, we examine the role of other customers supporting the users in delivering successful service.

\section{Study $1 \mathrm{~A}$}

\subsection{Method}

Study 1A was conducted to test the simple effect of the types of help on satisfaction $\left(\mathrm{H}_{1}\right)$. Study 1A tested whether receiving autonomyoriented help increases customer satisfaction compared to receiving dependency-oriented help. One hundred participants (62\% male, 37\% female) recruited through MTurk participated in the study. The sample consisted of participants in various age groups (38\% 20-29, 36\% 30-39, 15\% 40-49, and $11 \% 50$ or above). Although the sample consisted of participants across different 
groups, more than $60 \%$ of the participants reported that they use SSTs regularly, whereas only $9 \%$ of the participants reported that they rarely use SSTs. In addition, more than 70\% of the participants reported that they feel extremely competent and comfortable about SSTs. Thus, the sample is appropriate in testing our hypotheses.

Participants read a scenario in which they were told to assume that they are using a self checkout service at a grocery store nearby. The self check-out machine at groceries is one of the most common forms of SSTs. Participants were given a circumstance where they experience difficulty in using the self check-out machine and cannot figure out how to correct the problem. Participants were randomly assigned to either an 'autonomy-oriented help' or a 'dependencyoriented help' condition. In the autonomy-help condition, participants read a scenario where another customer passing by notices the frustration and offers a partial hint to the solution for them to solve on their own. In the dependency-help condition, participants read a scenario where another customer offers a full solution at hand to the problem (see Appendix for more detailed information).

After reading the scenario, participants completed a manipulation check item "What kind of help did you receive from the person?" on a 7-point scale (1 being the partial hint to the problem, 7 being the full solution to the problem). Participants then reported their satisfaction ("Overall, how satisfied are you with the firm?") as a dependent variable. In addition, participants reported their behavioral intentions, (1) switching ("I will switch to a competing service provider," "I will use the service from this service provider less than before," Cronbach's a = .90), and (2) negative word-of-mouth (NWOM; "I will discourage others to use this service provider.") adopted from Zeelenberg and Pieters (2004). All items were measured on a 7-point scale. Finally, participants provided demographic information (gender, age, and education).

\subsection{Results}

The manipulation check was successful. The main effect of the manipulated variable was significant for the types of help $(F(1,98)=$ 8.887, $p<.01)$. No other main or interaction effects were significant. None of the demographic information (gender, age, and education) was related to the focal variables, and thus it was excluded from further analyses.

As shown in Table 1, results revealed a significant effect of types of help on satisfaction toward the firm $(F(1,98)=2.987, p=.087)$, supporting $\mathrm{H}_{1}$. Specifically, participants in the autonomy help condition indicated higher satisfaction than those in the dependency help condition $\left(\mathrm{M}_{\text {autonomy help }}=4.14\right.$ vs. $\mathrm{M}_{\text {dependency help }}=$ 3.59). Participants in the autonomy help condition indicated lower intentions for switching $\left(\mathrm{M}_{\text {autonomy help }}=2.61\right.$ vs. $\left.\mathrm{M}_{\text {dependency help }}=3.45\right)$, and lower intentions for NWOM ( $\mathrm{M}_{\text {autonomy help }}$ 
〈Table 1〉 Effects of customer help on satisfaction and behavioral consequences (Study $1 \mathrm{~A}$ )

\begin{tabular}{|c|c|c|c|c|}
\hline \multicolumn{2}{|c|}{} & $\begin{array}{c}\text { Satisfaction } \\
\text { Toward Firm }\end{array}$ & $\begin{array}{c}\text { Switching } \\
\text { Intentions }\end{array}$ & $\begin{array}{c}\text { NWOM } \\
\text { Intentions }\end{array}$ \\
\hline \multirow{2}{*}{$\begin{array}{c}\text { Autonomy } \\
\text { Help }\end{array}$} & mean & $4.14^{*}$ & $2.61^{* * *}$ & $2.39^{* *}$ \\
\cline { 2 - 5 } & $\mathrm{SD}$ & 1.45 & 1.59 & 1.54 \\
\hline $\begin{array}{c}\text { Dependency } \\
\text { Help }\end{array}$ & mean & $3.59^{*}$ & $3.45^{* * *}$ & $3.00^{* *}$ \\
\cline { 2 - 5 } & $\mathrm{SD}$ & 1.69 & 1.85 & 1.78 \\
\hline
\end{tabular}

${ }^{*} p<.10,{ }^{* *} p<.05, * * * p<.01$

$=2.39$ vs. $\left.M_{\text {dependency help }}=3.00\right)$. As expected, compared to dependency help, autonomy help leads to higher customer satisfaction, lower level of switching intentions, and NWOM intentions. The results from Study $1 \mathrm{~A}$ were in line with previous literature on types of help that autonomy-oriented help is more effective and beneficial to the recipients. Although the results were statistically significant, we replicate the findings in Study $1 \mathrm{~B}$ to establish the robustness of the results.

\section{Study 1B}

\subsection{Method}

Study 1B was conducted to (1) replicate the findings from Study 1A, and to (2) find initial evidence for the mechanism behind such effects. Again, Study 1B tested whether receiving help increases satisfaction toward the firm $\left(\mathrm{H}_{1}\right)$. One hundred and forty one participants (48\% male,
52\% female) recruited through MTurk participated in the study. The sample consisted of participants in various age groups (36\% 20-29, 36\% 30-39, 17\% 40-49, and 16\% 50 or above). Participants were also from different race groups (74\% Caucasian, 9\% African American, 9\% Asian, 5\% Hispanic/Latino, and 3\% Others).

Again, we used the scenario used in Study 1A. Participants read a scenario in which they were told to assume that they are using a self check-out service at a grocery store nearby. Participants were randomly assigned to either an 'autonomy-oriented help' or a 'dependencyoriented help' condition (see Appendix for more detailed information).

After reading the scenario, participants completed a manipulation check item, "Which kind of help did the helper offer?" Participants then reported their satisfaction, and reported their thoughts about the situation, the firm, and the helper in a verbal protocol format. All items were measured on a 7-point scale. Finally, participants provided demographic information (gender, age, and education). 


\subsection{Results}

The manipulation check was successful. The main effect of the manipulated variable was significant for the types of help from other customers $(F(1,139)=13.41, p<.001)$. No other main or interaction effects were significant. None of the demographic information (gender, age, and education) was related to the focal variables, and thus it was excluded from further analyses.

Again, results revealed a significant effect of types of help on satisfaction toward the firm $(F(1,139)=13.83, p<.001)$, supporting $\mathrm{H}_{1}$. Specifically, participants in the autonomy help condition indicated higher satisfaction toward the firm than those in the dependency help condition $\left(\mathrm{M}_{\text {autonomy help }}=3.80\right.$ vs. $\mathrm{M}_{\text {dependency help }}=$ 3.23). The results were in line with the results from Study 1A, thus indicating the robustness of the findings.

The results of verbal protocol from the respondents were also analyzed to find preliminary evidence for the mechanism behind such effects. In line with our hypotheses, customers worried about their future usage when they received dependency-oriented help. For example, a respondent stated, "I was frustrated, but appreciative that the other customer stepped in to help. I will probably not do self-checkout again as I did not learn how to do it and would be apprehensive to do it the next time." Another similar quote was found as well: "I am really appreciative that this person took the time to help me figure it all out - but I would have rather he showed me what I did wrong and then let me fix it, so I won't run into this problem again." As found in these quotes, customers feel anxious about the future usage, and wish that another customer had given him/ her step-by-step instructions on how to use the technology. Other customers wrote quotes related to instrumentality of the help. A customer reported that he/she is "just glad that he/she got the problem solved," and another customer reported, "I would be very appreciative toward the customer who happened to see I was frustrated and came over to help me find a solution. His answer was a quick fix to what I needed."

As illustrated in the verbal protocol results, customers are anxious about using the service in the future, and think about how instrumental the help was when receiving help from other customers. To investigate this mechanism further, in Study 2, we investigate the underlying mechanisms of the relationship between the types of help and customer satisfaction.

\section{Study 2}

\subsection{Method}

Study 2 was conducted to examine (1) the mechanisms of the relationship between the 
types of help and customer satisfaction (H2), and (2) for which individuals such relationship is stronger or weaker (H3). One hundred participants (52\% male, 48\% female) recruited through MTurk participated in the study. The sample consisted of participants in various age groups (34\% between 20-29, 37\% between 30-39, 21\% between 40-49, and 9\% 50 or above) and various racial groups (75\% Caucasian, $8 \%$ African American, 8\% Asian/Pacific Islander, 6\% Hispanic/Latino, and 4\% others). Approximately, $80 \%$ of the participants reported that they feel extremely competent and comfortable about using SSTs, thus indicating the appropriateness of the sample for testing our hypotheses.

The study employed a single factor design: 2 (types of help: autonomy vs. dependency oriented help) between-subjects design. Types of help were manipulated with two versions of scenarios. Participants read a scenario in which they were told to assume that they are using the self-order kiosks at a restaurant. Participants were randomly assigned to either an 'autonomy help' or a 'dependency help' condition. In the autonomy help condition, participants read a scenario where another customer passing by notices their frustration and offers a partial hint to the problem by giving them step-by-step instructions. In the dependency help condition, participants read a scenario where another customer passing by notices your struggle and offers full solution to the problem by taking over your screen and completing the order for you. (see Appendix for more information).

After reading the scenario, participants completed a manipulation check item on a 7-point scale, "What kind of help did you receive from the person?" Participants then indicated the extent they felt anxiety in the situation, and the perceived instrumentality ("Please indicate whether you believe that the help from another customer enabled your problem solving.") In addition to these two mediators, participants reported their self-esteem to rule out an alternative explanation. Participants indicated satisfaction toward the firm, and their need for dominance (adapted from the Jackson Personality Research Form (PRF); e.g., "I tend to dominate the conversation," "I am generally a leader than a follower," "Other people tend to seek my opinions on things," "I am pretty good at getting my way in most things," Cronbach's a $=.88$ ). All items were measured on a 7-point scale. Finally, participants provided demographic information (gender, age, and education).

\subsection{Results}

The manipulation check was successful. The main effect of the manipulated variable was significant for the types of help $(F(1,98)=$ 11.99, $p<.01)$. No other main or interaction effects were significant. None of the demographic information (gender, age, and education) was related to the focal variables, and thus it was excluded from further analyses. 
Results revealed a significant effect of types of help on satisfaction toward the firm $(F(1,98)$ $=13.83, p<.001$ ), supporting $\mathrm{H}_{1}$. Specifically, participants in the autonomy help condition indicated higher satisfaction toward the firm than those in the dependency help condition $\left(\mathrm{M}_{\text {autonomy help }}=4.10\right.$ vs. $\left.\mathrm{M}_{\text {dependency help }}=2.84\right)$.

To test the mediation effect, we employed a bootstrapping method, using Hayes' (2012) PROCESS macro. We used the types of help (autonomy vs. dependency) as an independent variable, satisfaction as a dependent variable, and (1) anxiety and (2) instrumentality as mediators. The 95\% confidence interval was computed using the bootstrapping method with 5,000 samples. According to Hayes (2012), an indirect effect is significant when the confidence interval does not include 0 , and insignificant when it includes 0 . The effects of instrumentality (95\% CI: - 1.20, - .23) and anxiety (95\% CI: - .73, - .12) mediating the relationship between the types of help and satisfaction were significant, supporting $\mathrm{H}_{2-1}$ and $\mathrm{H}_{2-2}$. The findings indicated that the types of help had a significant influence on satisfaction via instrumentality and anxiety simultaneously. On the other hand, a mediation analysis of self-esteem in the relationship between the types of help and satisfaction yielded no significant result (95\% CI: -.23, .15), including 0 in the confidence interval. Taken together, the bootstrapping results supported our hypothesis that both instrumentality and anxiety were the mechanisms underlying the relationship between the types of help and satisfaction.

To test the moderated mediation effect of need for dominance via anxiety and instrumentality, we conducted a bootstrapping test with 5,000 samples (Model 7). The moderation effect of need for dominance was insignificant $(95 \% \mathrm{CI}$ : - .27, .01) for the model including anxiety, which rejects $\mathrm{H} 3-2$. On the other hand, the moderation effect of need for dominance was significant (95\% CI: .03, .21) for the model including instrumentality, which supports H3-1. For those lower in need for dominance, the effect of types of help on instrumentality was stronger than for those higher in need for dominance. A mediation effect using a median split was also analyzed to investigate the differential effects between those high and low in need for dominance. Those low in their need for dominance reported higher instrumentality towards autonomy help ( $\mathrm{M}_{\text {high }}=6.19$ vs. $\mathrm{M}_{\mathrm{low}}=$ 6.00), and reported lower instrumentality towards dependency help $\left(\mathrm{M}_{\text {high }}=3.21\right.$ vs. $\left.\mathrm{M}_{\text {low }}=4.45\right)$, thus indicating that the effect is stronger for those low in need for dominance. As explained earlier, those high in need for dominance (vs. low in need for dominance) would be less affected by the types of help because when received help from others, it has already violated their needs to dominate the situation and technology. Nevertheless, even for those high in need for dominance, the effect of types of help held. The statistical model is presented in Figure 1, 
〈Figure 1〉 Dual mediation model (Study 2)

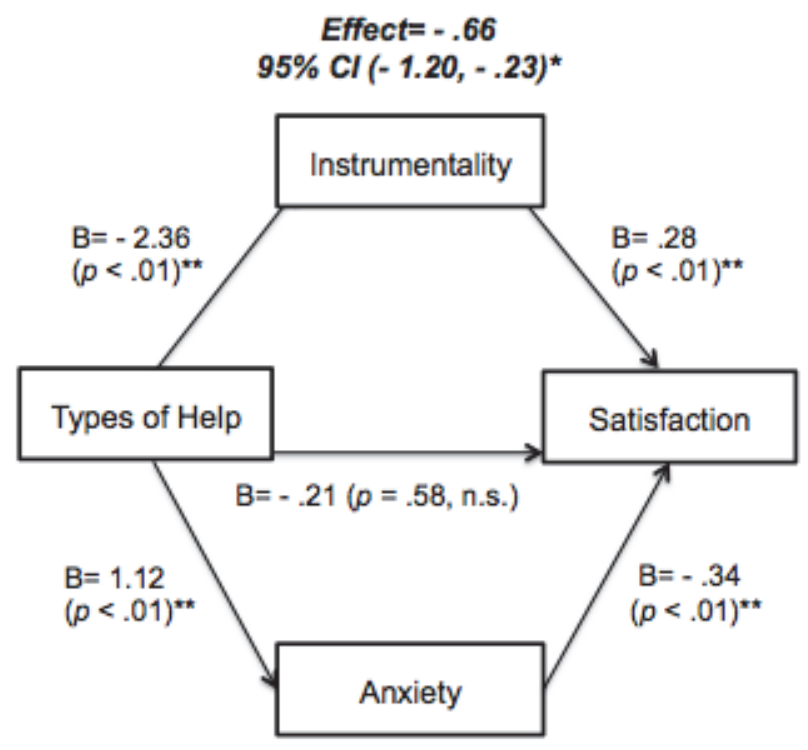

Effect $=-.38$

$95 \% \mathrm{Cl}(-.73,-.12)^{\star}$

〈Figure 2〉 Moderated mediation model (Study 2)

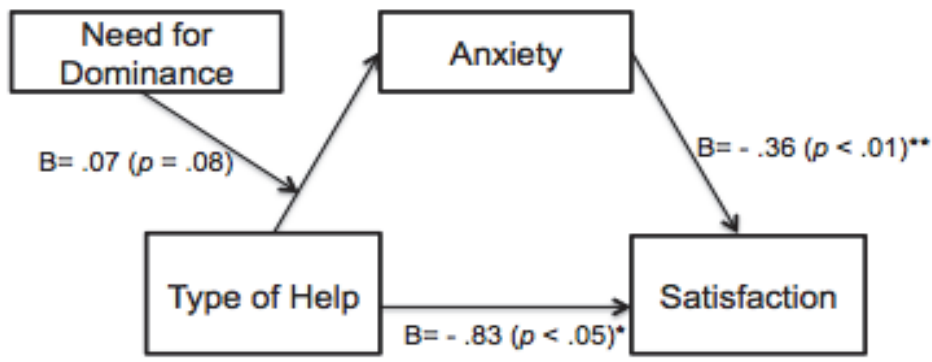

$95 \% \mathrm{Cl}(-.0683, .0028)$

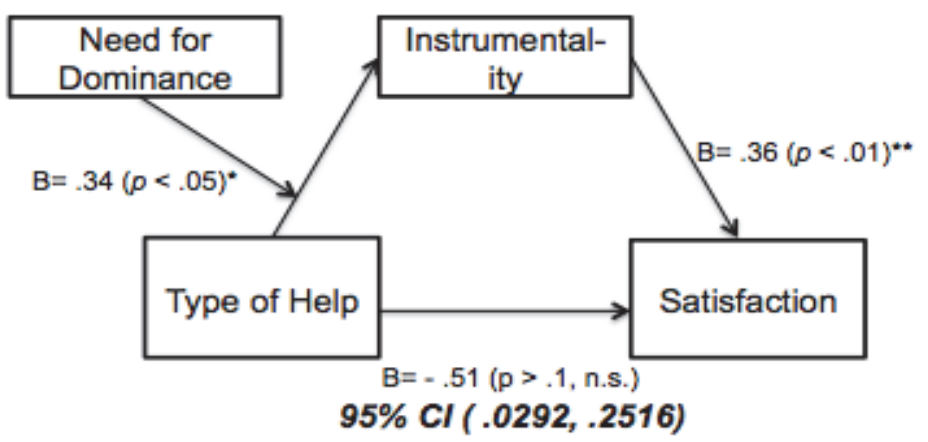

14 ASIA MARKETING JOURNAL Vol. 18 No. 02 July 2016 
and the moderation effect with a median split is presented in Figure 2.

A possible explanation for the insignificant moderation effect of need for dominance on anxiety might be that need for dominance is more related to the cognitive aspect of the situation. Perceived control is an appraisal and evaluation of the situation, and thus, need for dominance might only affect the cognitive path and might not affect the affective path. Future research could further investigate this issue in examining the role of need for dominance in the relationship between the types of help and customer satisfaction.

\section{Discussion}

Human beings are social animals, and various types of support in the society are essential to human well-being (Fyrand et al. 2002; Helgeson 2003). Service firms are also encouraging customer participation and inter-customer support for productivity gains of the firm (Lovelock and Young 1979) by defining customers as "partial employees" and active "co-producers." However, receiving help from other customers would not always increase satisfaction during service encounters. Depending on the types of help received from others, customers would experience different levels of satisfaction. In the current research, we focus on the two types of help, autonomy- and dependency- oriented help to investigate their differential impacts during service deliveries. Results from the three experimental studies showed that receiving autonomy- (vs. dependency-) oriented help leads to higher customer satisfaction through a dual path, instrumentality of the help and anxiety for future usage, which represent cognitive and affective path respectively.

\subsection{Theoretical Contributions}

The present research contributes to the academia in several ways. First, the current research contributes to the helping literature by extending the concept of types of help in the services marketing context. Previous research on the types of help focused on inter-group helping interactions (e.g., Nadler 2002), but research on the types of help during inter-personal helping interactions is relatively limited. In the current research, we examine the effect of the types of help during inter-customer relationships to fill this gap. The current research serves as an initial effort to investigate the types of help in inter-personal helping during service encounters. In addition, results from our studies suggested a dual mechanism in the effect of the types of help on customer satisfaction. The results revealed that autonomy-oriented help increases customer satisfaction through higher instrumentality and lower anxiety, suggesting that cognitive and affective path work simultaneously. This dual 
mechanism explanation goes beyond the traditional explanations that focused on self-related mechanisms, such as self-esteem (e.g., Nadler 2002).

Second, the current research adds to the CCB literature by investigating a specific type of CCB, helping other customers. Inter-customer helping has become more common during service encounters due to the prevalence of SSTs in the market. Firms are minimizing the number of employees, and thus during SST settings, customers are highly likely to seek help from other customers. Despite the importance, researchers' efforts to understand inter-customer helping was minimal. Therefore, the current research addressed this neglected dimension. To broaden our understanding of inter-customer helping, the current research utilized the concept of autonomy- vs. dependency-oriented help in the helping literature to define different types of help during inter-customer helping, and investigated their impact on customer satisfaction.

\subsection{Managerial Implications}

Inter-customer helping as a form of customer participation has become more important in the current service environment where SSTs are replacing the traditional service encounters. Most firms are aware that they should encourage helping among customers. However, firms should pay attention not only to encouraging inter-customer helping per se, but also to understanding how customers provide help to each other (e.g., types of help). This is because not all helps are created equal. Depending on the types of help received, help from other customers could be threatening, and this directly leads to customer satisfaction toward firms.

Results from the current research suggested that depending on the types of help received, customers would experience different levels of satisfaction toward the firm. In particular, customers in general prefer autonomy-oriented help to dependency-oriented help. Because the types of help influence customer satisfaction through both cognitive and affective paths, an understanding of inter-customer helping is critical for managers of service firms. There are several ways firms could utilize the findings from the current research. First, at the store level, firms could figure out ways to educate customers to provide autonomy-oriented help by providing exemplary behaviors through employee behaviors. In addition, firms could utilize psychological and/or financial rewards. For example, customers who have assisted other customers could be recognized as the 'superhero of the week' to further encourage them to get involved in $\mathrm{ac}^{-}$ tive inter-customer helping. Recognition would be awarded to those whose recipients reported the greatest satisfaction for the help, and this would lead customers to help each other in a way that would not threaten the recipients. Second, at the corporate level, firms should generate marketing strategies to facilitate autonomy-ori- 
〈Figure 3〉 Moderation Effect: The effect of need for dominance on instrumentality (Study 2)

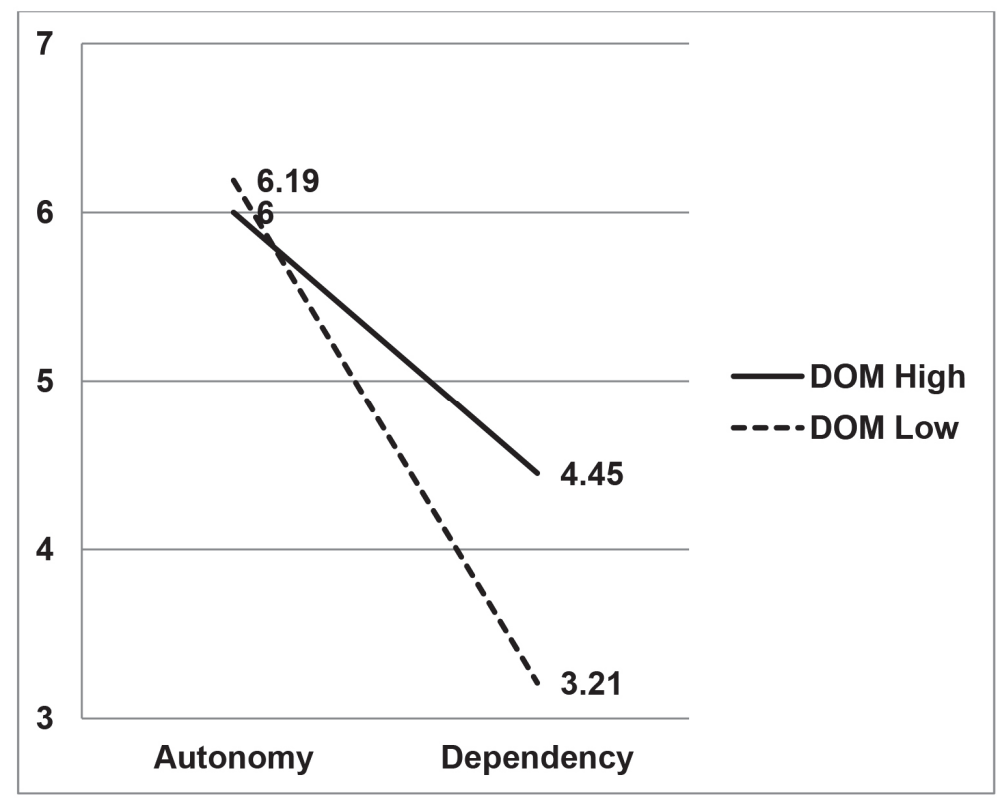

ented help among customers. In the long run, firms should transform their corporate culture to be customer-oriented and thus, encourage the "right" type of helping among customers. Finally, customers with high need for dominance are less influenced by the types of help received. Thus, firms could implement proper strategies to specific target customers to encourage proper types of inter-customer helping.

\subsection{Limitations and Future Research}

Although the current research provides several new insights to the literature, limitations do exist as well. First, in examining the underlying mechanisms for the relationship between the types of help and customer satisfaction, we used a single-item scale to measure anxiety and instrumentality. Although a single-item scale has its benefits such as convenience and prevention of response fatigue for participants, a multi-item scale also has its benefits. Future research could replicate the current findings using a multi-item scale to ensure robustness of the findings. Nonetheless, the current research makes an important step toward understanding the effect of types of help on customer satisfaction, and adds valuable insights through suggesting two different mechanisms: cognitive path and affective path. Second, we have conducted three studies all of which were experimental studies, but future research could use various methodologies to investigate the current topic. For example, probing actual customers through qual- 
itative studies would also help understand customer behavior when receiving help from others. Finally, the results from Study 2 suggested that the moderation effect of need for dominance was only significant for the cognitive path. Future research could investigate this phenomenon to understand the overall effect of need for dominance in the current framework.

Future research could address various other issues regarding the types of help, such as boundary conditions for the effect of the types of help on customer satisfaction. For example, perceived harm to others during service encounters is high when individuals witness a line of customers waiting for them to complete the service delivery process. When an individual perceives the harm to others is high, he/she would focus on escaping from the situation in a timely manner. Thus, he/she would prefer dependency-oriented help (vs. autonomy-oriented help) due to the shortened time for successful service delivery. Another boundary condition suggested is the types of a task, whether it is a routine task or a one-time task. When future usage is salient, individuals would prefer to learn the process and receive autonomy-oriented help so that they would not have to worry about learning it again in the future. Although most people use SSTs in a daily routine, such as self check-out services at groceries and ATMs, some people regress back to using the traditional services after experiencing failures during their initial usage. Finally, future research could examine the effect of unsolicited help vs. solicited help. When customers receive help from others during service encounters, whether helpseeking took place or not could also affect recipient's reactions. The current research focuses on unsolicited help. However, if the help was solicited, customers might prefer dependencyoriented help because their focus on escaping from the situation promptly.

〈Received June 8. 2016〉 〈Accepted August 3. 2016〉

\section{References}

Alvarez, Katherina and Esther van Leeuwen (2011), "To Teach or to Tell? Consequences of Receiving Help from Experts and Peers," European Journal of Social Psychology, 41 (3), 397-402.

Bartol, Kathryn M. (1974), "Male versus Female Leaders: The Effect of Leader Need for Dominance on Follower Satisfaction," Academy of Management Journal, 17(2), 22533.

Brehm, Jack W. (1966), A Theory of Psychological Reactance. Oxford, England: Academic Press.

Brickman, Philip, Rabinowitz Vita Carulli, Karuza Jurgis Jr., Coates Dan, Cohn Ellen, and Kidder Louise (1982), "Models of Helping and Coping," American Psychologist, 37(4), 
368-84.

Coates, Dan, Gary J. Renzaglia and Marlowe C. Embree (1983), "When Helping Backfires: Help and Helplessness," in New Directions in Helping: Recipient Reactions to Aid. Fisher, Jeffrey, Arie Nadler, and Bella M. DePaulo eds. New York: Academic Press, 251-79.

Collier, Joel E. and Sheryle E. Kimes (2013), "Only If It Is Convenient: Understanding How Convenience Influences Self-Service Technology Evaluation," Journal of Service Research, 16(1), 39-51.

Deelstra, Janna T., Maria C. W. Peeters, Wilmar B. Schaufeli, Wolfgang Stroebe, Fred R. H. Zijstra, and Loren P. van Dooren (2003), "Receiving Instrumental Support at Work: When Help is Not Welcome," Journal of Applied Psychology, 88(2), 324-31.

Egloff, Boris, Stefan C. Schmukle, Lawrence R. Burns, and Andreas Schwerdtfeger (2006), "Spontaneous Emotion Regulation during Evaluated Speaking Tasks: Associations with Negative Affect, Anxiety Expression, Memory, and Physiological Responding," Emotion, 6(3), 356-66.

Fitzsimons, Grainne M. and James Y. Shah (2008), "How Goal Instrumentality Shapes Relationship Evaluations," Journal of Personality and Social Psychology, 95(2), 31937.

Fyrand, Live, Torbjorn Moum, Arnstein Finset, and Anne Glennas (2002), "The Impact of
Disability and Disease Duration on Social Support of Women with Rheumatoid Arthritis," Journal of Behavioral Medicine, 25 (3), 251-68.

Gough, Harrison G. (1957), California Psychology Inventory Manual. Palo Alto: Consulting Psychologists Press.

Groth, Markus (2005), "Customers as Good Soldiers: Examining Citizenship Behaviors in Internet Service Deliveries," Journal of Management, 31(1), 7-27.

Hayes, Andrew F. (2012), "PROCESS: A versatile computational tool for observed variable mediation, moderation, and conditional process modeling," retrieved from http:// www.afhayes.com/public/process2012.pdf.

Helgeson, Vicki S. (2003), “Social Support and Quality of Life," Quality of Life Research, 12(1), 25-31.

Homburg, Christian, Nicole Koschate, and Wayne D. Hoyer (2006), "The Role of Cognition and Affect in the Formation of Customer Satisfaction: A Dynamic Perspective," Journal of Marketing, 70(3), 21-31.

Hui, Chen, Cynthia Lee and Denise M. Rousseau (2004), "Psychological Contract and Organizational Citizenship Behavior in China: Investigating Generalizability and Instrumentality," Journal of Applied Psychology, 89(2), 311-21.

Jackson, Douglas N. (1974), The Personality Research Form. Port Huron: Research Psychologists Press. 
Johnson, Devon and Kent Grayson (2005), "Cognitive and Affective Trust in Service Relationships," Journal of Business Research, 58(4), 500-7.

Karabenick, Stuart A. (1998), Strategic Help Seeking: Implications for Learning and Teaching. Mahwah: Erlbaum.

Labroo, Aparna A. and Sara Kim (2009), “The "Instrumentality" Heuristic: Why Metacognitive Difficulty Is Desirable During Goal Pursuit," Psychological Science, 20(1), 12734.

Lazarus, Richard S. and James R. Averill (2013), "Emotion and Cognition: With Special Reference to Anxiety," in Anxiety: Current Trends in Theory and Research, Spielberger, Charles D. eds. New York, NY: Academic Press, pp. 242-78.

Lovelock, Christopher H. and Robert H. Young (1979), "Look to Consumers to Increase Productivity," Harvard Business Review, 57(May-June), 168-78.

Kelly, Petranka, Jennifer Lawlor, and Michal Mulvey (2013), "Customer Decision-making Processes and Motives for Self-Service Technology Usage in Multi-Channel Hospitality Environments," International Journal of Electronic Customer Relationship Management, 7(2), 2013

MacIntrye, Peter D. (2002), "Motivation, Anxiety and Emotion in Second Language Acquisition," in Individual Differences in Second Language Acquisition, Robinson eds. Ams- terdam: Benjamins. 45-68.

Meuter, Matthew L. and Mary Jo Bitner (1998), "Self-Service Technologies: Extending Service Frameworks and Identifying Issues for Research," in AMA Winter Educators' Conference Proceedings, Dhruv Grewal and Connie Pechmann, eds. Chicago: American Marketing Association, 12-19.

Meuter, Matthew L., Amy L. Ostrom, Robert I. Roundtree, and Mary Jo Bitner (2000), "Self-Service Technologies: Understanding Satisfaction with Technology-Based Service Encounters," Journal of Marketing, 64(3), 50-64.

Miao, Li and Anna S. Mattila (2013), "The Impact of Other Customers on Customer Experiences: A Psychological Distance Perspective," Journal of Hospitality \& Tourism Research, 37(1), 77-99.

Mills, Peter K. and James H. Morris (1986), "Clients as "Partial" employees of Service Organizations: Role Development in Client Participation," Academy of Management Review, 11(4), 726-35.

Mooradian, Todd A. and James M. Olver (1997), "I Can't Get No Satisfaction: The Impact of Personality and Emotion on Postpurchase Processes," Psychology \& Marketing; 14(4), 379-93.

Nadler, Arie (1997), "Personality and Helpseeking: Autonomous versus Dependent Seeking of Help," in Sourcebook of Theory and Research on Social Support and Per- 
sonality, Pierce, G., Lakey, B., Sarason, I. G. and Sarason B., eds. New York: Plenum, $379-407$.

Nadler, Arie (2002), "Inter-Group Helping Relations as Power Relations: Maintaining or Challenging Social Dominance between Groups through Helping," Journal of Social Issues, 58(3), 487-502.

Nadler, Arie, Avram Altman, and Jeffrey D. Fisher (1979), "Helping is not Enough: Recipient's Reactions to Aid as a Function of Positive and Negative Information about the Self," Journal of Personality, 47(4), 615-28.

Nadler, Arie and Samer Halabi (2006), "Intergroup Helping as Status Relations: Effects of Status Stability, Identification, and Type of help on Receptivity to High-Status Group's Help," Journal of Personality and Social Psychology, 91(1), 97-110.

Oliver, Richard L. and John E. Swan (1989), "Equity and Disconfirmation Perceptions as Influences on Merchant and Product Satisfaction," Journal of Consumer Research, 16(3), 372-83.

Rosenbaum, Mark S. and Carolyn A. Massiah (2007), "When Customers Receive Support from Other Customers: Exploring the Influence of Intercustomer Social Support on Customer Voluntary Performance," Journal of Service Research, 9(3), 257-70.

Sigala, Marianna (2009), "E-Service Quality and Web 2.0: Expanding Quality Models to
Include Customer Participation and InterCustomer Support," Service Industries Journal, 29(10), 1341-58.

Simoni, Jane M., Howard S. Adelman, and Perry Nelson (1991), "Perceived Control, Causality, Expectations and Help-Seeking Behavior," Counseling Psychology Quarterly, 4(1), 3744.

Van Leeuwen, Esther and Susanne Tauber (2010), "The Strategic Side of Out-Group Helping," in The Psychology of Prosocial Behavior: Group Processes, Intergroup Relations, and Helping, Stumer, Stefan and Mark Snyder, eds. Chichester, UK: WileyBlackwell, 81-98.

Van Leeuwen, Esther, Susanne Tauber, and Kai Sassenberg (2011), "Knocking on the Outgroup's Door: Seeking Outgroup Help under Conditions of Task or Relational Conflict," Basic and Applied Social Psychology, 33(3), 266-78.

Yi, Youjae (2014), Customer Value Creation Behavior. New York: Routledge.

Yi, Youjae and Taeshik Gong (2008a), "If Employees 'Go the Extra Mile,' do Customers Reciprocate with Similar Behavior?" Psychology \& Marketing, 25(10), 961-86.

Yi, Youjae and Taeshik Gong (2008b), "The Effects of Customer Justice Perception and Affect on Customer Citizenship Behavior and Customer Dysfunctional Behavior," Industrial Marketing Management, 37(7), 767-83. 
Zeelenberg, Marcel and Rik Pieters (2004), "Beyond Valence in Customer Dissatisfaction: A Review and New Findings on Behavioral
Responses to Regret and Disappointment in Failed Services," Journal of Business Research, 57(4), 445-55. 


\section{〈Appendix〉}

\section{Scenarios used in Study 1A, 1B}

You are at a grocery store nearby your house. You pick up a few grocery items and decide to use the self check-out machine for a quick check-out. However, the grocery store updated their self check-out system a few days ago. Because you are not familiar with the new system, you hit a wrong button and cannot figure out how to correct the problem. You look around and there is a long line of customers waiting for you to finish checking out. You are frustrated that you have no idea how to fix the problem.

1) Autonomy-oriented Help: There are others standing by you, however, no one offers you help to solve the problem you have with the check-out process. You try hitting a few buttons to get back to the screen where you need to be. However, you fail to proceed with the rest of the procedure and cannot complete the check-out process.

2) Dependency-oriented Help: A customer passing by notices you, and comes over. He says, "Try clicking on the button at the corner to start the check-out process." Following his instruction, you click on the button, and you are back to the screen where you needed to be. You go ahead, proceed with the rest of the procedure, and complete the check-out process.

\section{Scenarios used in Study 2}

You are at a restaurant nearby your house to spend your time with colleagues. You enter the restaurant, and you decide to use the self-order kiosks for a faster process. However, it seems like the restaurant recently launched their self-order system to offer more options for customization. Because there were too many options appearing on the screen, you are not able to figure out how to use the system correctly. You look around and there was a line of customers waiting for you to finish ordering. You are frustrated that you have no idea how to use the system.

1) Autonomy-oriented Help: A customer passing by notices that you are frustrated. He comes over and asks you, "What are you trying to order?" Following your response, he says, "Try looking under the menu on the left first and then move on to the right." Following his instructions, you click on the options. After a few attempts, you succeed in completing the order.

2) Dependency-oriented Help: A customer passing by notices that you are frustrated. He comes over and asks you, "What are you trying to order?" Following your response, he takes over your screen and clicks on the buttons on the screen without giving you a step-by-step instruction. After clicking on several options on the screen, he finally succeeds in making an order for you. 